\title{
Comparative susceptibility of Atlantic salmon, lake trout and rainbow trout to Myxobolus cerebralis in controlled laboratory exposures
}

\author{
V. S. Blazer ${ }^{1, *}$, C. L. Densmore ${ }^{1}$, W. B. Schill ${ }^{1}$, D. D. Cartwright ${ }^{2}$, S. J. Page ${ }^{1}$ \\ ${ }^{1}$ National Fish Health Research Laboratory and ${ }^{2}$ Water Resources Division, \\ US Geological Survey, 11700 Leetown Road, Kearneysville, West Virginia 25430, USA
}

\begin{abstract}
The susceptibility of lake trout Salvelinus namaycush, rainbow trout Oncorhynchus mykiss and Atlantic salmon Salmo salar to Myxobolus cerebralis, the causative agent of whirling disease, was compared in controlled laboratory exposures. A total of 450 (225 for each dose) fry for each species were exposed to a low (200 spores per fish) or high (2000 spores per fish) dose of the infective triactinomyxon. At $22 \mathrm{wk}$ post-exposure, 60 fish from each group, as well as controls for each species, were examined for clinical signs (whirling behavior, blacktail, deformed heads and skeletal deformities), microscopic lesions, and presence of spores. Rainbow trout were highly susceptible to infection, with $100 \%$ being positive for spores and with microscopic pathological changes in both exposure groups. Rainbow trout were the only species to show whirling behavior and blacktail. Atlantic salmon were less susceptible, with only 44 and $61 \%$ being positive for spores, respectively, in the low and high dose groups, while 68 and $75 \%$, respectively, had microscopic pathology associated with cartilage damage. Rainbow trout heads contained mean spore concentrations of 2.2 (low dose) or 4.0 (high dose) $\times 10^{6}$ spores $g$ tissue $^{-1}$. The means for positive Atlantic salmon (not including zero values) were 1.7 (low) and 7.4 (high) $\times 10^{4}$ spores g tissue ${ }^{-1}$. Lake trout showed no clinical signs of infection, were negative for spores in both groups and showed no histopathological signs of $M$. cerebralis infection.
\end{abstract}

KEY WORDS: Whirling disease $\cdot$ Rainbow trout $\cdot$ Atlantic salmon $\cdot$ Lake trout $\cdot$ Myxobolus cerebralis

\section{INTRODUCTION}

Since reports in the mid-1990s that severe population declines of wild trout were attributed to Myxobolus cerebralis, the causative agent of whirling disease (Nehring \& Walker 1996, Vincent 1996), much research has been directed towards the understanding of this disease. One research area of prime importance to resource managers is assessing the susceptibility of different salmonid species and strains. Early speciessusceptibility studies (Hoffman \& Putz 1969, O'Grodnick 1979) were conducted prior to an understanding of the parasite's complex life cycle, which was reported by Markiw \& Wolf (1983) and Wolf \& Markiw (1984). This cycle involves the oligocheate Tubifex tubifex which becomes infected when ingesting $M$. cere- bralis spores from the remains of infected fish. Infected T. tubifex release the triactinomyxon (TAM) spore, the infective stage for salmonid fish species. Controlled studies with known concentrations of the infective TAMs were not possible prior to the elucidation of this cycle.

In recent years, the susceptibility of various rainbow trout Oncorhynchus mykiss strains, brown trout Salmo trutta, brook trout Salvelinus fontinalis, cutthroat trout $O$. clarki, bull trout $S$. confluentus and Arctic grayling Thymallus arcticus to Myxobolus cerebralis have been assessed (El-Matbouli et al. 1999, Hedrick et al. 1999a,b, Thompson et al. 1999, Densmore et al. 2001). There are contradictory literature reports as to the susceptibility of lake trout $S$. namaycush. Hoffman \& Putz (1969) reported that lake trout in live-boxes 
receiving water in which diseased fish had previously been found showed typical signs of whirling disease. However, no histopathology or spore counts were presented, nor was there any information on the age of the fish at exposure or dose of infective TAMs. O'Grodnick (1979) compared the susceptibility of 7 salmonid species to natural infections of Myxobolus cerebralis and used clinical signs, histopathology, and spore counts to assess susceptibility. Lake trout were the only species that showed no clinical or histopathological signs and for which no spores were obtained from cranial tissue. However, again, there was no information on fish age or infective dose. More recently, Wagner et al. (2002) reported that $13.6 \%$ of lake trout exposed to 1000 TAMs per fish were positive for spores at 20 wk postexposure.

There is little information regarding the susceptibility of Atlantic salmon Salmo salar to Myxobolus cerebralis. A number of review articles list Atlantic salmon as a susceptible species in feral populations and fish hatcheries in Europe, Asia and the Far East, but not in the United States (Halliday 1976, El-Matbouli et al. 1992). However, we have found no well-documented studies where spore counts and histopathology demonstrate susceptibility or resistance of this species. Since the commercial culture of Atlantic salmon is a mass-market commodity (Forster 2002), it is necessary to understand the potential for this species to carry, and possibly spread, $M$. cerebralis.

The purpose of this study was to compare the susceptibility of rainbow trout, Atlantic salmon and lake trout to infection with Myxobolus cerebralis in controlled, laboratory exposures. Development of clinical signs, as well as spore production and histopathological responses, were compared among species and exposure levels.

\section{MATERIALS AND METHODS}

Fish. Experimental fishes were received at the Leetown facility as eyed eggs and hatched in verticaltray incubators supplied with flow-through, degassed, oxygenated, and TAM-free spring water $\left(19 \mathrm{l} \mathrm{min}^{-1}\right.$, $12^{\circ} \mathrm{C}$, total hardness of $425 \mathrm{mg} \mathrm{l}^{-1}$ ). Rainbow trout Oncorhynchus mykiss (Mt. Lassen domestic stock) were obtained from a private hatchery in California. This strain was chosen because of its known susceptibility to Myxobolus cerebralis and previous use in experimental trials as a standard control strain (Hedrick et al. 1999a,b, Densmore et al. 2001). Atlantic salmon Salmo salar eggs (Troutsprings domestic stock) came from a private hatchery in Washington, and lake trout Salvelinus namaycush eggs (Seneca strain) came from a state hatchery in Pennsylvania.
Myxobolus cerebralis spores were obtained from cranial cartilage of naturally infected rainbow trout from a private hatchery in southwestern Virginia. Spores were fed to aquatic oligochaetes (approximately $85 \%$ Tubifex tubifex) collected from Sleepy Creek (Morgan County, West Virginia) and maintained as a stock population in the laboratory. The TAMs were collected through water filtration with a $50 \mu \mathrm{m}$ wire-mesh sieve, counted by microscopic examination of a sample aliquot, and concentrations were adjusted to achieve exposure levels of 200 (low) or 2000 (high) TAMs fish ${ }^{-1}$.

Experimental exposures of trout. Fish were exposed to TAMs at 5 to 7 wk post-hatch. The degree days at time of exposure were 1208 for lake trout, 1165 for Atlantic salmon, and 1173 for rainbow trout. A total of 450 fry (225 per dose) of each fish species were exposed to TAMs in gently aerated water for $2 \mathrm{~h}$. Following exposure, fish were divided into triplicate $30 \mathrm{l}$ tanks with 75 fish $\operatorname{tank}^{-1}$. An additional 150 fish of each species were sham exposed for $2 \mathrm{~h}$ and placed in

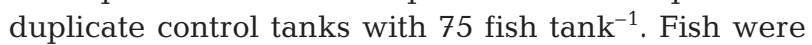
fed a commercial salmon starter feed at $5 \%$ body weight $\mathrm{d}^{-1}$ and monitored daily for mortality and other indicators of disease.

Assessment of infection. Clinical signs: At $22 \mathrm{wk}$ post-exposure, 60 fish were sampled from each control and exposure level (20 per exposed tank; 30 per control tank). The exception to this was the control Atlantic salmon for which 15 fish tank $^{-1}$ were sampled. Fish were randomly selected 5 at a time, placed individually in $5 \times 37 \mathrm{l}$ aquaria, and observed for whirling behavior and blacktail. Fish were then euthanized with a lethal dose of tricaine methanesulfonate (Finquel, Argent Chemical Laboratories), weighed, measured and examined for any apparent morphological abnormalities (cranial, opercular and skeletal deformities; shortened opercles).

Histopathology: Heads, including gills, were bisected longitudinally and half of the head was preserved in Davidson's fixative, while the other half was individually frozen at $-20^{\circ} \mathrm{C}$ for spore enumeration. The remaining portion of the fish was fixed for 2 to $3 \mathrm{~d}$ in Davidson's solution and then placed in $70 \%$ alcohol until processing. Two to 3 gill arches, half the head and a section through the body, approximately midway to the caudal fin, were examined from each fish. Tissues from all exposed and control fish were embedded in paraffin, and cut and stained with hematoxylin and eosin (H\&E) and Giemsa (Luna 1992). A grading scheme of 0 to 5, as described in Bartholomew (2001), was used to score cranial (included gill arch and opercle) lesions, based on the abundance of spores, vegetative stages of the parasite, and inflammatory or degenerative changes to cartilage and surrounding tissues. 
Briefly, Grade 0 contained no abnormalities associated with whirling disease; Grade 1 contained small, discrete foci of cartilage degeneration with little associated inflammation; Grade 2 had single extensive focus or several smaller foci of cartilage necrosis with localized inflammation; Grade 3 contained multiple foci with moderate inflammation that extended minimally into surrounding tissues; Grade 4 had multifocal to coalescing areas of affected cartilage with extensive inflammation extending into surrounding tissues; Grade 5 had multifocal, coalescing areas characterized by loss of normal architecture and extensive inflammation.

Spore enumeration: Spores were enumerated in 18 fish from each exposure level for each species (6 from each TAMexposed tank and 9 from each control tank), collected at 22 wk post exposure. Fish used for spore enumeration were randomly chosen for rainbow trout and Atlantic salmon. For lake trout, those fish that showed morphological changes (1 control, 4 low and 6 high dose) were used for spore counts. Frozen halfhead samples were subjected to a modification of the pepsin trypsin digestion of Markiw \& Wolf (1974), as described by Densmore et al. (2001). Spore concentrations were determined based on hemacytometer counts, and the number of spores per gram of tissue (wet wt) reported.

Statistical analyses. Two-sample $t$-tests and 1-way ANOVA were used to verify that significant differences of body weight, total length and histological grade did not exist among replicate tanks of a given treatment. Next, differences among treatment groups within a given species were tested using 1-way ANOVA. When differences were found, the NewmanKeuls multiple-range test was used to identify which variable(s) contributed to the overall significant outcome. Differences among species at a given treatment level were tested in the same way. However, because all lake trout measurements were 0 for histological grade and spore counts, 2-sample $t$-tests were used to compare Atlantic salmon and rainbow trout data for these 2 variables. Significance was defined at the 0.05 level.

\section{RESULTS}

\section{Mortalities}

All mortalities appeared to be incidental and not due to whirling disease. Mortality levels of rainbow trout and lake trout were below $7 \%$ for all groups. Rainbow trout deaths were $6.1,1.3$ and $1.3 \%$, respectively, for the control, low and high exposure groups, while for lake trout they were $1.6,1.3$ and $3.1 \%$, respectively. Significantly higher mortalities were noted in the Atlantic salmon; however, these also did not appear to be related to whirling disease. Losses of 26.6, 13.3 and $20.0 \%$ were observed in the control, low and high groups, respectively.

\section{Clinical signs}

No clinical signs were observed in any control fish. Whirling behavior (43.3 and 58.3\% in low and high doses, respectively) and blacktail (0 and $3.3 \%$ in the low and high doses, respectively) were only observed in rainbow trout (Table 1). Cranial deformities were observed in a low percentage (8.3 and 3.3\% in low and high groups, respectively) of exposed Atlantic salmon versus the high percentages observed in exposed rainbow trout 75 and $73.3 \%$, respectively, in the low and high groups). Cranial deformities were also noted in 5 exposed lake trout (Table 1). Shortened opercles were observed in $25 \%$ of both the low and high dose exposed Atlantic salmon, and none in the control group. In comparison, shortened opercles were only observed in the high-dose rainbow trout $(6.6 \%)$. Lake trout had shortened opercles in all groups, consisting of $1.6,5.0$, and $5.0 \%$ in control, low and high groups, respectively.

It was interesting to note that there were no significant differences between exposure groups (control, low and high dose) in total length or weight of either Atlantic salmon or lake trout $(p>0.05)$. However, ex- 


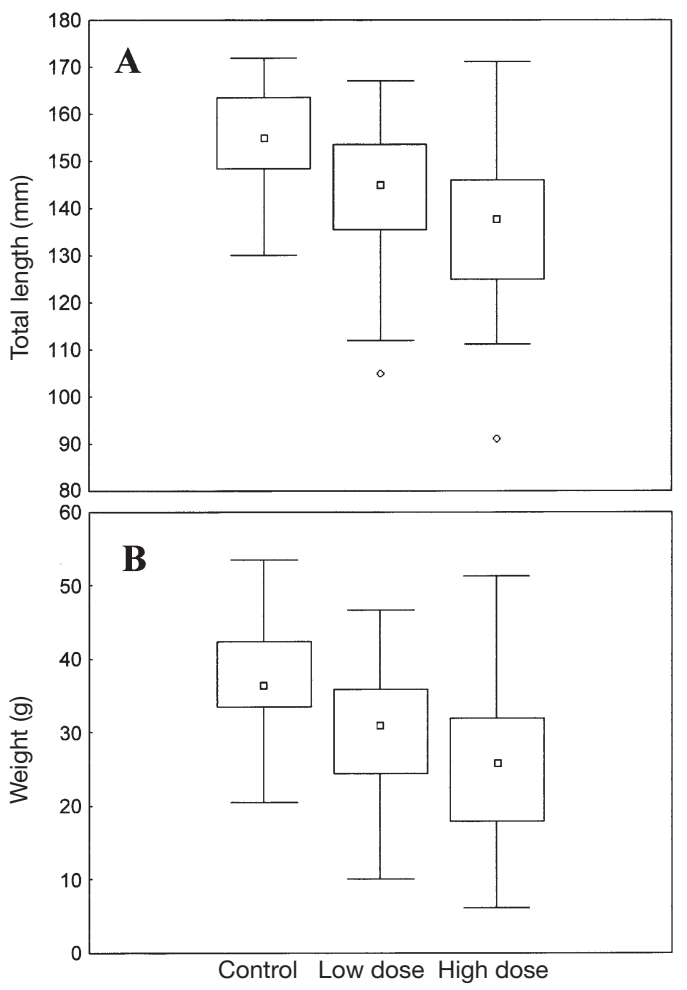

Fig. 1. Oncorhynchus mykiss. Box plots of rainbow trout (A) lengths and (B) weights measured $22 \mathrm{wk}$ post-exposure to Myxobolus cerebralis. Controls were sham-exposed, low and high dose groups were exposed for $2 \mathrm{~h}$ to 200 or 2000 triactinomyxon spores fish ${ }^{-1}$, respectively. Center box: median; outer box: 25 to 75 percentile; bars: range for non-outliers; circles: outliers. All groups were significantly different $(\mathrm{p}<0.05)$ from one another

posure to Myxobolus cerebralis significantly affected the growth of rainbow trout. The control group was significantly larger (both total length and weight) than the low dose group $(p<0.0001)$, which was significantly larger $(\mathrm{p}=0.004)$ than the high dose group (Fig. 1).

\section{Spore concentrations}

No spores were found in any control fish of any species. All of the rainbow trout tested contained spores. The mean $( \pm \mathrm{SE})$ number of spores for the low dose fish was $2.2( \pm 0.5) \times 10^{6}$ and ranged from 0.24 to 6.33 $\times 10^{6}$ spores $\mathrm{g}^{-1}$. There were significantly $(\mathrm{p}=0.02)$ more spores observed in the high dose fish. The mean number of spores $\mathrm{g}^{-1}$ in the high exposure group was $4.0( \pm 0.7) \times 10^{6}$ and ranged from $0.36 \times 10^{6}$ to $12.03 \times$ $10^{6}$. Only 44.4 and $61.1 \%$ of the low and high dose Atlantic salmon were positive for spores, respectively. Spore counts for those that were positive from the low dose group ranged from $0.46 \times 10^{4}$ to $2.66 \times 10^{4}$ (mean
$1.7 \pm 0.25 \times 10^{4}$ ), and for those that were positive from the high dose ranged from $1.00 \times 10^{4}$ to $23.36 \times 10^{4}$ (mean $7.4 \pm 2.4 \times 10^{4}$ ). Again, there was a significant difference between the high and low exposure groups $(p=0.01)$. No spores were found in any of the lake trout.

\section{Microscopic pathology}

No control fish of any species were observed to contain spores, vegetative stages or inflammation associated with necrotic or degenerative cartilage. There were also no spores or whirling disease-associated abnormalities observed in the cranial area of either exposed lake trout group.

All rainbow trout of both exposure levels had Myxobolus cerebralis-associated lesions, with severity grades ranging from 2 to 4 in the low dose group (mean $\pm \mathrm{SE} ; 3.0 \pm 0.10)$ and 2 to $5(3.5 \pm 0.09)$ in the high dose group (Fig. 2). These 2 groups were significantly different $(p<0.0001)$. Lesions were most common in the cranium, followed by the vertebrae and gill arch. The inflammatory response was primarily a granulomatous response (Fig. 3A insert), and often extended into the surrounding tissue (Fig. 3A).
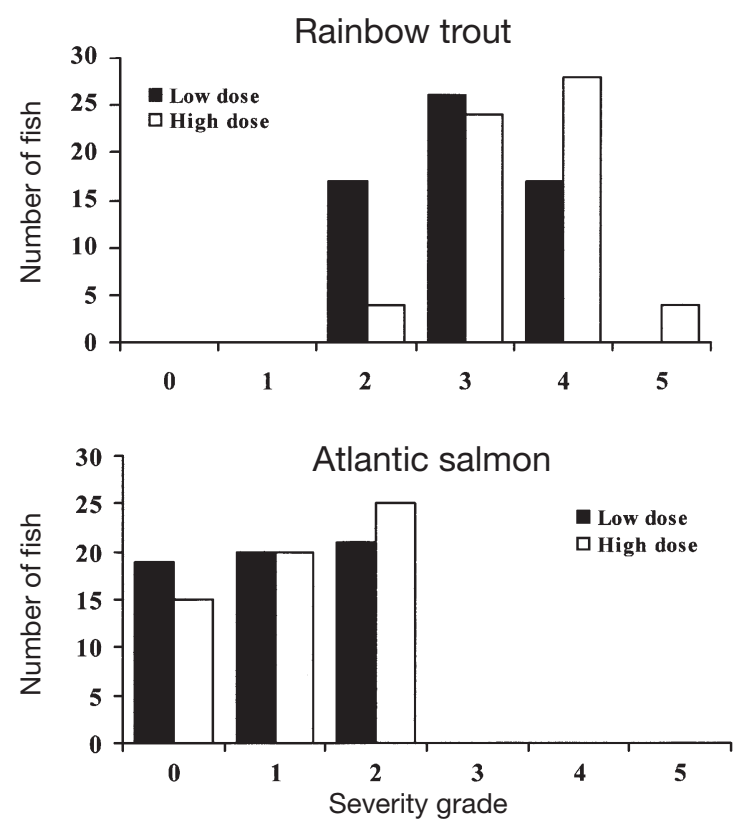

Fig. 2. Distribution of microscopic pathology severity grades among exposure groups of rainbow trout Oncorhynchus mykiss and Atlantic salmon Salmo salar 22 wk post-exposure to low (200 spores fish ${ }^{-1}$ ) and high (2000 spores fish ${ }^{-1}$ ) concentrations of triactinomyxon spores of Myxobolus cerebralis. Bars represent the number of each fish (from a total of 60) with that grade 
Fig. 3. Myxobolus cerebralis. Microscopic pathology associated with infection in (A) rainbow trout Oncorhynchus mykiss and (B) Atlantic salmon Salmo salar. (A) Extensive inflammation, vegetative stages and mature spores of the parasite (a) replace affected cartilage (b), and extend into the surrounding tissues of rainbow trout (arrow). Insert shows a higher magnification of the granulomatous inflammation (a) and presence of the parasite (arrow). Scale bar $=150$ and $50 \mu \mathrm{m}$ for insert. (B) Inflammation around affected cartilage in Atlantic salmon included a granulomatous response (a) and eosinophilic granular cells (arrow). Scale bar $=$
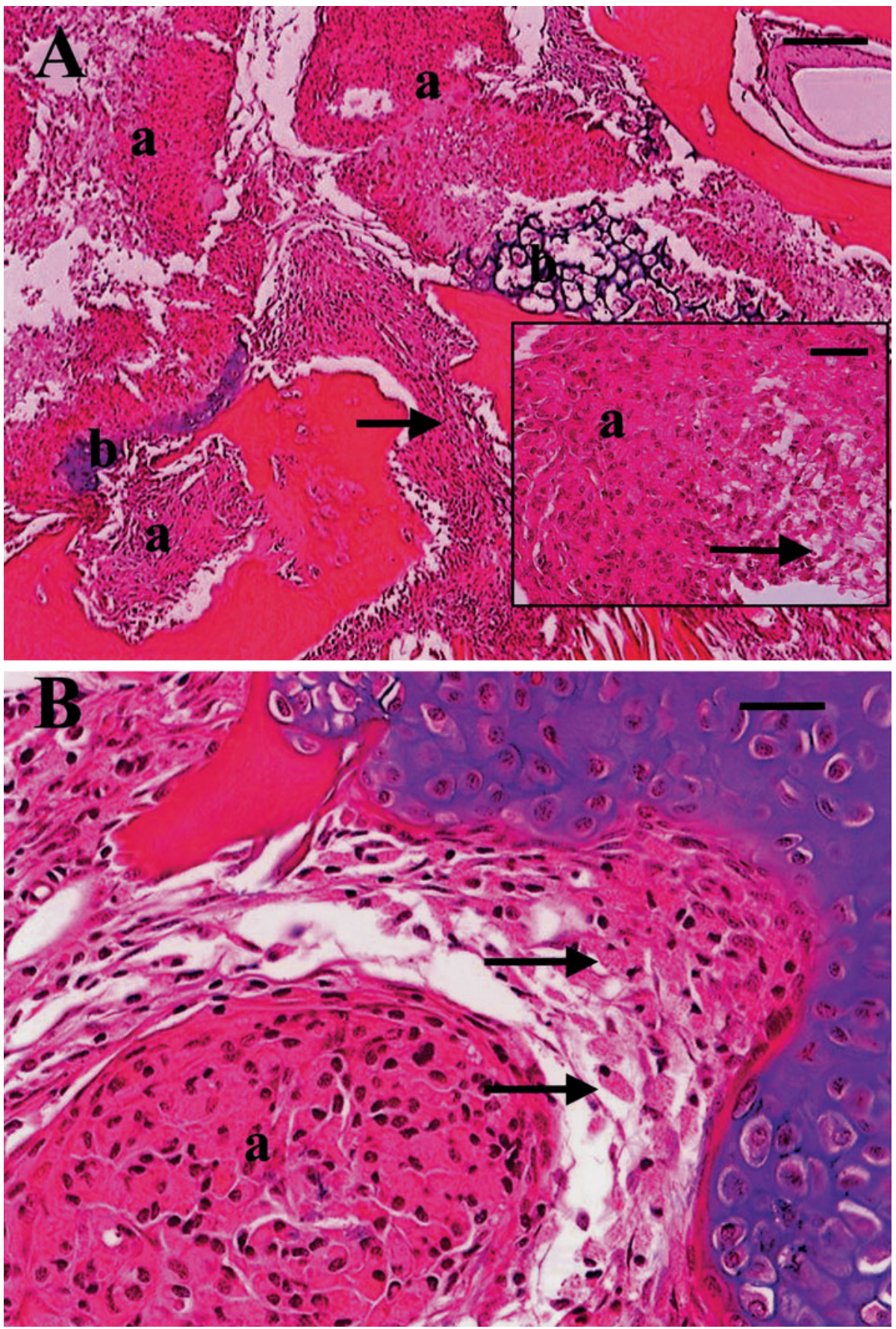

Fewer Atlantic salmon had microscopic lesions due to Myxobolus cerebralis (Table 2). In addition, the histopathological severity scores of those that had lesions were lower than those of rainbow trout (Fig. 2). The mean grades for the low and high dose fish (only using those that were graded 1 or higher) was $1.5 \pm$ 0.08 and $1.6 \pm 0.07$, respectively. Thus, there was no significant difference between the microscopic patho- logy grades of the low and high doses in Atlantic salmon. Lesions were most commonly observed in the cartilage of the gills and opercles, and much less commonly in the cranial and spinal areas. Although granulomatous inflammation, similar to that in rainbow trout, was observed, eosinophilic granular leukocytes were also commonly observed around affected cartilage (Fig. 3B), as well as in cranial nerve tissue (Fig. 4A). An 
Table 2. Incidence of infection with Myxobolus cerebralis in rainbow trout Oncorynchus mykiss, Atlantic salmon Salmo salar and lake trout Salvelinus namaycush 22 wk postexposure to low (200) or high (2000) concentrations of triactinomyxon spores per fish, based on spore counts or microscopic pathology. Low dose groups were exposed to 200 triactinomyxons per fish, high dose to 2000 per fish

\begin{tabular}{|ccccc|}
\hline Species & Dose & $\begin{array}{c}\text { Spores } \\
(\% \text { positive }) \\
(\mathrm{n}=18)\end{array}$ & $\begin{array}{c}\text { Pathology } \\
(\% \text { positive }) \\
(\mathrm{n}=60)\end{array}$ & $\begin{array}{c}\text { Mean severity } \\
\text { grade (positive } \\
\text { fish only) }\end{array}$ \\
\hline Rainbow & Low & 100 & 100 & 3.0 \\
trout & High & 100 & 100 & 3.5 \\
Atlantic & Low & 44 & 68 & 1.5 \\
salmon & High & 61 & 75 & 1.6 \\
Lake & Low & 0 & 0 & 0 \\
trout & High & 0 & 0 & 0 \\
\hline
\end{tabular}

observed in 44.4 and $61.1 \%$ of the low and high dose Atlantic salmon tested. In addition, those that were positive had approximately 2 orders of magnitude lower concentrations of spores per gram of cranial tissue when compared to rainbow trout.

Rainbow trout had moderate to severe histological changes in the cranium and around the inner ear, which would account for the whirling behavior and high incidence of deformed heads. Conversely, Atlantic salmon rarely had affected cartilage in the area of the inner ear, and whirling behavior was not observed in this species. The differences between rainbow trout and Atlantic salmon in microscopic pathology are very similar to the differences between rainbow trout and brown trout reported by Hedrick et al. (1999a). As in brown trout, Atlantic salmon had an eosinophilic response was not observed in rainbow trout. In a number of Atlantic salmon that were negative for spores (4 low dose and 4 high dose), cartilage damage and inflammation was present but no spores were observed histologically (Fig. 4B).

\section{DISCUSSION}

Rainbow trout and Atlantic salmon were both susceptible to Myxobolus cerebralis. However, Atlantic salmon was clearly a more resistant species. Clinical signs, such as whirling behavior and blacktail, were only seen in rainbow trout. Cranial deformities were seen in both species, although at a significantly lower prevalence in Atlantic salmon when compared to rainbow trout. All exposed rainbow trout contained spores, regardless of exposure concentration. Conversely, spores were only

Fig. 4. Microscopic pathology observed in Atlantic salmon Salmo salar after exposure to Myxobolus cerebralis. (A) Large numbers of eosinophilic granular cells were observed in connective tissue around bone and cartilage (thick arrows) and within nerve bundles (thin arrow). Scale bar $=50 \mu \mathrm{m}$. (B) Atlantic salmon at $22 \mathrm{wk}$ post-exposure to $M$. cerebralis triactinomyxon spores. No spores were observed in digests of head or by microscopic examination of fixed tissue. However, areas of affected cartilage with an infiltration of eosinophilic granular cells (a) were noted. Scale bar $=30 \mu \mathrm{m}$

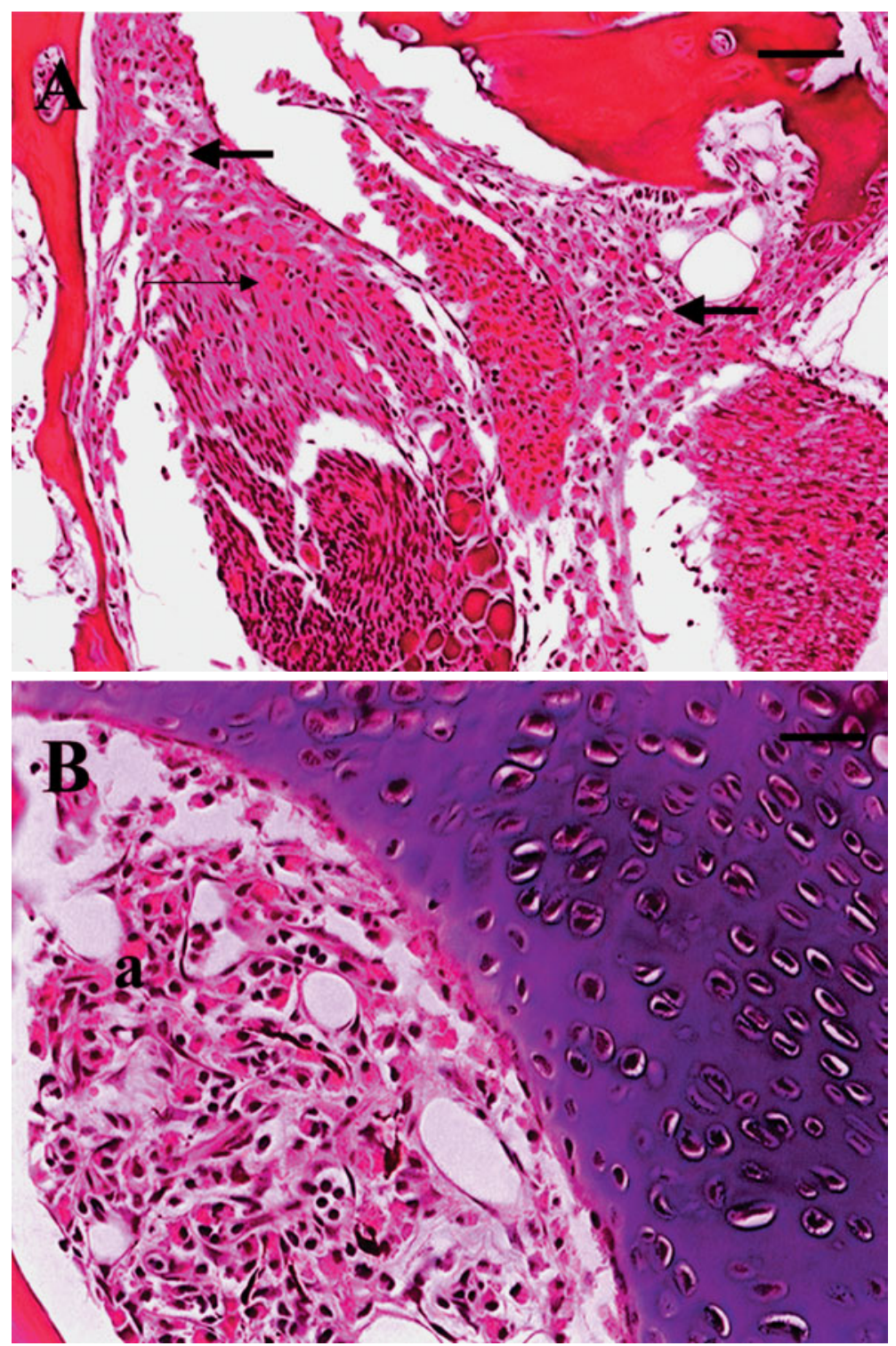


extensive eosinophilic response in and around nerves and affected cartilage. Control Atlantic salmon also had eosinophilic granular cells (although to a much lesser extent than infected fish) in the connective tissue and in and around nerve tissue in the cranial area. These cells were not observed in control rainbow trout or lake trout. It is obvious that the parasite is able to migrate to the cartilaginous tissue of the head in Atlantic salmon. Possibly the eosinophilic response, in combination with the granulomatous (macrophage) response, is able to clear the infection in some instances.

It appears from this and other studies $\left(\mathrm{O}^{\prime}\right.$ Grodnick 1979) that certain strains of lake trout are refractory to Myxobolus cerebralis, at least at levels up to 2000 TAMs fish ${ }^{-1}$. Other strains, such as reported by Wagner et al. (2002), appear to be somewhat susceptible. In that study, lake trout were exposed at 10.5 wk posthatch (slightly older than those of the current study) and exposed to $1000 \mathrm{TAMs}_{\mathrm{fish}}{ }^{-1}$. Hence, the difference in susceptibility does not appear to be due to age at exposure or TAM density. It is interesting to note that $100 \%$ of exposed lake trout were positive or weakly positive by PCR, 5 wk after exposure. However, at $20 \mathrm{wk}$, only $13.6 \%$ were found to be positive by spore enumeration (Wagner et al. 2002). This suggests, as do our results, that lake trout may have some ability to clear the infection, even though the parasite can invade and initially infect. In the current study, we saw no microscopic pathology to indicate that the sporoplasm had progressed to the cartilage. This suggests that innate factors in the skin or nervous system may be able to clear the infection. It would then follow that environmental factors or other stressors, leading to immunosuppression or reduced disease resistance, could significantly influence susceptibility/ resistance.

In conclusion, the 3 species of salmonids tested ranged from the highly susceptible rainbow trout, to intermediate susceptible Atlantic salmon, to the refractory lake trout. Rainbow trout have been extensively studied for their response to Myxobolus cerebralis, and strain differences have been observed (Densmore et al. 2001). Strain differences in Atlantic salmon and lake trout may also occur, and need to be further studied. The inflammatory responses of rainbow trout and Atlantic salmon differed, and this may account for some of the differences in susceptibility. The fact that Atlantic salmon can be infected and contain spores without overt clinical indications suggests that this species could represent a potentially unapparent means of $M$. cerebralis transmission. Ongoing studies are attempting to determine whether environmental factors and immunosuppression may increase the susceptibility of lake trout.
Acknowledgements. The authors thank Thomas Waldrop for initial care of experimental fish, and Kathryn Spring and Darlene Bowling for histological preparations. This work was funded in part by a Cooperative Agreement from the Fish and Wildlife Service.

\section{LITERATURE CITED}

Bartholomew JL (ed) (2001) Standard protocols for whirling disease research, Version 1. Standardized Protocols Advisory Committee, Whirling Disease Foundation and Fish Health Section, American Fisheries Society, Bozeman, MT, p 9-10

Densmore CL, Blazer VS, Cartwright DD, Schill WB and 6 others (2001) A comparison of susceptibility to Myxobolus cerebralis among strains of rainbow trout and steelhead in field and laboratory trials. J Aquat Anim Health 13: 220-227

El-Matbouli M, Fischer-Scherl T, Hoffmann RW (1992) Present knowledge on the life cycle, taxonomy, pathology, and therapy of some Myxosporea spp. important for freshwater fish. Annu Rev Fish Dis 3:367-402

El-Matbouli M, Hoffmann RW, Schoel H, McDowell TS, Hedrick RP (1999) Whirling disease: host specificity and interaction of the actinosporean stage of Myxobolus cerebralis and rainbow trout Oncorhynchus mykiss. Dis Aquat Org 35:1-12

Forster J (2002) Farming salmon: an example of aquaculture for the mass market. Rev Fish Sci 10:577-591

Halliday MM (1976) The biology of Myxosoma cerebralis: the causative organism of whirling disease of slamonids. J Fish Biol 9:339-357

Hedrick RP, McDowell TS, Gay M, Marty GD, Georgiadis MP, MacConnell E (1999a) Comparative susceptibility of rainbow trout Oncorhynchus mykiss and brown trout Salmo trutta to Myxobolus cerebralis, the cause of whirling disease. Dis Aquat Org 37:173-183

Hedrick RP, McDowell TS, Mukkatira K, Georgiadis MP, MacConnell E (1999b) Susceptibility of selected inland salmonids to experimentally induced infections with Myxobolus cerebralis, the causative agent of whirling disease. J Aquat Anim Health 11:330-339

Hoffman GL, Putz RE (1969) Host susceptibility and the effect of aging, freezing, heat, and chemicals on spores of Мyхоsoma cerebralis. Prog Fish-Cult 31:35-37

Luna LG (1992) Histopathologic methods and color atlas of special stains and tissue artifacts. American Histolabs, Gaithersburg, MA

Markiw ME, Wolf K (1974) Myxosoma cerebralis: isolation and concentration from fish skeletal elements-sequential enzymatic digestion and purification by differential centrifugation. J Fish Res Board Can 31:15-20

Markiw ME, Wolf K (1983) Myxosoma cerebralis (Myxozoa: Myxosporea) etiologic agent of salmonid whirling disease requires tubificid worm (Annelida: Oligochaeta) in its life cycle. J Protozool 30:561-564

Nehring RB, Walker PG (1996) Whirling disease in the wild: the new reality in the intermountain west. Fisheries (Bethesda) 21:28-32

O'Grodnick JJ (1979) Susceptibility of various salmonids to whirling disease (Myxosoma cerebralis). Trans Am Fish Soc 108:187-190

Thompson KG, Nehring RB, Bowen DC, Wygant T (1999) Field exposure of seven species or subspecies of salmonids to Myxobolus cerebralis in the Colorado River, Middle Park, Colorado. J Aquat Anim Health 11:312-329 
Vincent ER (1996) Whirling disease and wild trout: the Montana experience. Fisheries (Bethesda) 21:32-34

Wagner E, Arndt R, Brough M, Wilson C, Nelson G (2002) Survival, performance, and resistance to Myxobolus cerebralis infection of lake trout X brook trout. N Am J

Editorial responsibility: Wolfgang Körting,

Hannover, Germany
Fish Manag 22:760-769

Wolf K, Markiw ME (1984) Biology contravenes taxonomy in the Myxozoa: new discoveries show alteration of invertebrate and vertebrate hosts. Science 225: 1449-1452

Submitted: March 31, 2003; Accepted: August 10, 2003

Proofs received from author(s): January 2, 2004 